\title{
A Study on Generation of 3D Model and Mesh Image of Excavation Work using UAV
}

\author{
D.H. Kim ${ }^{\mathrm{a}}$, S.W. Kwon ${ }^{\mathrm{b}}$, S.W. Jung ${ }^{\mathrm{c}}$, S. Park ${ }^{\mathrm{d}}$, J.W. Park ${ }^{\mathrm{e}}$ and J.W. Seo \\ ${ }^{a}$ Department of Convergence Engineering for Future City, Sunkyunkwan University, Republic of Korea \\ ${ }^{b}$ School of Civil \& Architectural Engineering, Sungkyunkwan University, Republic of Korea \\ ${ }^{c}$ Department of Convergence Engineering for Future City, Sunkyunkwan University, Republic of Korea \\ ${ }^{\mathrm{d}}$ Korea Plant Management, Republic of Korea

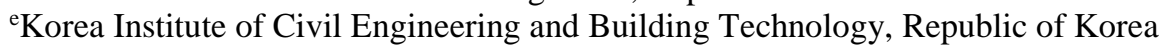 \\ e Civil Engineering, Hanyang University, Republic of Korea \\ E- \\ mail: kdh1945@skku.edu, swkwon@skku.edu, suwanx@nate.com, missmr72@gmail.com, jwpark@kict.re.kr, ise \\ o@hanyang.ac.kr
}

\begin{abstract}
Recently, advanced and semi-automated equipment is used for earthwork project. For automated and intelligent earthwork management, surveying method needs to be improved and updated to acquire and store on-site information. Unmanned Aerial Vehicles (UAVs) was considered as an important technology and using UAVs in various areas are prominent area in recent times. Unmanned Aerial vehicles (UAVs), aerial movable image sensing platform, have become the area that has been becoming notable in all industries. Miniature UAVs can measure the imagery taken form aerial and detect environment data. This study aims to determine the optimal algorithm based on meshed surface from arbitrary imagery acquired by UAVs and generate $3 \mathrm{D}$ model for analyzing and getting earthwork on site. Study results are aimed to generate ground control data based on imagery information in earthwork project.
\end{abstract}

Keywords -Miniature Unmanned Aerial Vehicles (UAVs), Optimal algorithm, Generating 3D model, Earthwork

Instructions; Authors; ISARC 2015

\section{Introduction}

At present, in construction process, dependability of construction machinery equipment has been increased day by day and diversified construction equipments are mobilized and operated but decreased productivity and occurrence of various safety accident due to lack of inter-equipment communication and working information provision, construction error of unskilled workers and accumulated survey error are indicated as a general problem in the construction industry.

In particular, during construction of earthwork being required in most of the construction project, it is a current situation that on-site productivity is very low and wrong construction is taken place frequently due to lack of communication between equipment-manager, equipment-equipment. In addition, as the work is suspended due to survey work during construction and the work considering collaboration among various equipment group is not performed, development of systemized civil engineering technology to improve such practice is required on site.

In other words, in large-scaled earthwork project in which a lot of construction equipment are mobilized, development of a new technology that may improve construction quality, productivity and economic efficiency through construction equipment informatization and operational efficiency is required.

In this study, in order to solve this problem, a study on generation of civil 3D model and mesh image using UAV is intended to be performed in large-scaled earthwork project (housing land, road, airport, harbor) as a part of general technology based on construction equipment control system that makes operation and work of construction machinery equipment (excavator, bulldozer, grader, dump truck, roller, loader) to be informatized and efficient.

\section{Preparation of the Manuscript}

\subsection{Scope of Research}

Recently, advanced and semi-automated equipment is used for earthwork project. For automated and intelligent earthwork management, surveying method needs to be improved and updated to acquire and store 
on-site information.

Unmanned Aerial Vehicles (UAVs) was considered as an important technology and using UAVs in various areas are prominent area in recent times. Unmanned Aerial vehicles (UAVs), aerial movable image sensing platform, have become the area that has been becoming notable in all industries. Miniature UAVs can measure the imagery taken form aerial and detect environment data.

This study aims to determine the optimal algorithm based on meshed surface from arbitrary imagery acquired by UAVs and generate 3D model for analyzing and getting earthwork on site. Study results are aimed to generate ground control data based on imagery information in earthwork project.

\subsection{Analysis of Research Trend}

Present research progression and direction of relevant research area were identified by analyzing 3 typical theses after selecting them through investigation of relevant literature.

Control of Housing Attitude of a Quadrotor with Shifted Center of Gravity for Inspection of High-rise Structures $^{[1]}$

Use of quad rotor that is vertically moving device among UAVs. As optimal scanning result could be obtained only when hovering (aerial stop) location of quadrotor should be stably positioned, a research on its function was performed. Objective of measuring the result of altitude retention through Fuzzy PSO method (simulation) is to control hovering altitude for performing correct scanning using quadrotor of UAV.

\section{Generation of 3D Model built-up by using quadrotor $^{[2]}$ \\ 2 types of existing 3D modeling method was} presented and compared. First, as a method of utilizing hexacopter and specific software of UAVs, a single actual building image was expressed by combining photo information obtained from 3D modeling and UAV. Cost is saved but its disadvantage is that it takes a lot of time.

Second, as a method of utilizing Cropcam in which blade is attached to drone, it is very useful in terms of time saving when comparing it with widely known other devices.

In this study, quadrotor loaded with Gopro Hero 3 camera was used. By utilizing high definition camera, photograph is taken and total model is generated by integrating designated feature points of stored photos.

Texture and Scale in Object-based Analysis of Subdecimeter Resolution Unmanned Aerial Vehicle (UAV) Imagery ${ }^{[3]}$
Objective of this study is to determine most suitable texture and optimal division scale for differentiating herbaceous plant, shrub and earth of dry land through image obtained by utilizing UAV.

First, image object through texture measurement after image division based on RGB value (Red, Blue, Green) was calculated by using GLCM statics (3x3.5x5, etc.) in a pixel-based analysis and by utilizing Definiens Professional 5 in object-based image analysis.

\subsection{Research Method}

The research methodology for the proposed article focuses on:

1. Research

- Comparison and analysis on related research developments on UAVs technologies

- Set a target performance (criteria performance) of this research

- The selection and verification of optimal aerial movable image sensing platform

2. Development of optimal algorithm and derivation of object extraction process

- Obtaining information of on-site imagery and establishing the process of defining the surface mesh - Development of technology of collecting object information

\section{Equipment Selection}

\subsection{Comparison and analysis on related research development on UAVs technologies}

Before starting this study, current reality of UAV drone being developed in the market at present was surveyed. Aerial movable image sensing platform-based UAVs have become an area that draws attention from all the relevant industries and through miniature UAVs, it has been designed to enable aerial image photographing and environmental data sensing that were failed to be measured so far. Only a few years ago, miniature UAV technology was utilized on the level of just hobby but recently, it stands out as a key technology in diversified industrial areas. ${ }^{[4]}$

Typical UAV being developed in Korea is 2 types. First, Korea Electronics Technology Institute developed air node of gasoline engine type and it is composed of a structure considering portability, transportability, safety and durability based on personal portable flight robot. Its operation time is quite long as $\mathbf{4 5}$ minutes and it was developed so that hovering is enabled for its rotor blade 
type and $802.11 \mathrm{n}$ supported $2.4 \mathrm{GHz} / 5 \mathrm{GHz}$ dual band wireless communication module is loaded together with CCD camera built-in and position, posture, velocity value being measured by GPS and MSM inertial sensor module could be transmitted. ${ }^{[5]}$

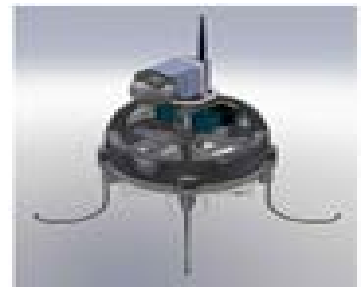

Figure 1 Air node

(Development of Korea Electreonics Technology Institute)

Table 1 Specifications of Air node

\begin{tabular}{c|c}
\hline Power sources & Gasoline \\
\hline Control range & $2 \mathrm{~km}$ \\
\hline Hours & $45 \mathrm{~min}$ \\
\hline Payload & $1 \mathrm{~kg}$ \\
\hline
\end{tabular}

In addition, $\mathrm{X}$ drone is manufacturing miniature UAV of quad rotor type enabling auto-pilot with maximum payload up to $10 \mathrm{~kg}$ and merchandising it mainly for usage of aerial photographing, facility and forest fire, destruction monitoring through manufactured product but most of the products are manufactured by assembling overseas components.

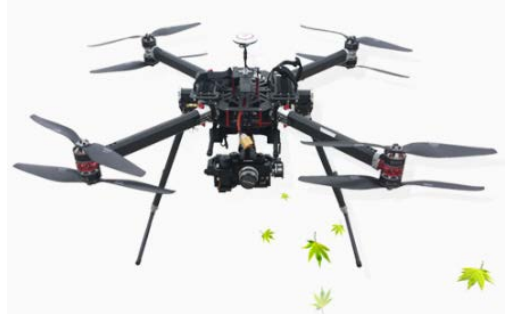

Figure $2 \mathrm{X}$ drone

Table 2 Specifications of $\mathrm{X}$ drone

\begin{tabular}{c|c}
\hline size & $980 \mathrm{~mm}$ \\
\hline weight & $5.3 \mathrm{~kg}$ \\
\hline material & carbon \\
\hline control range & $50 \mathrm{~km}$ \\
\hline $\begin{array}{c}\text { maximum } \\
\text { speed }\end{array}$ & $102 \mathrm{~km}$ \\
\hline $\begin{array}{c}\text { maximum } \\
\text { altitude }\end{array}$ & $3000 \mathrm{~m}$ \\
\hline
\end{tabular}

\begin{tabular}{c|c}
\hline flight time & $80 \mathrm{~min}$ \\
\hline payload & $10 \mathrm{~kg}$ \\
\hline
\end{tabular}

Besides, UAV technology of aerial movable image sensing platform is being actively developed in overseas and products of diversified standards are developed and sold.

Table 3 Other UAV Products

\begin{tabular}{|c|c|c|c|}
\hline features & $\begin{array}{l}\text { Aeryon } \\
\text { Scout }\end{array}$ & $\begin{array}{l}\text { AirRobot } \\
\text { Ar-100b }\end{array}$ & $\begin{array}{l}\text { Microdrone } \\
\text { s } \\
\text { MD4- } 1000 \\
\end{array}$ \\
\hline Size & $1 \mathrm{~m}$ & $1 \mathrm{~m}$ & $0.8 \mathrm{~m}$ \\
\hline Payload & $0.4 \mathrm{~kg}$ & $0.2 \mathrm{~kg}$ & $1 \mathrm{~kg}$ \\
\hline Weight & $1.4 \mathrm{~kg}$ & $1 \mathrm{~kg}$ & $4 \mathrm{~kg}$ \\
\hline Equipment & outdoor & outdoor & outdoor \\
\hline Flight time & $20 \mathrm{~min}$ & $15 \mathrm{~min}$ & 20min \\
\hline $\begin{array}{l}\text { Maximum } \\
\text { speed }\end{array}$ & $50 \mathrm{~km} / \mathrm{h}$ & $18 \mathrm{~km}$ & $50 \mathrm{~km}$ \\
\hline Flight time & 20min & $15 \mathrm{~min}$ & $20 \mathrm{~min}$ \\
\hline $\begin{array}{c}\text { Wind } \\
\text { Resistance }\end{array}$ & $6 \mathrm{~m} / \mathrm{s}$ & $4 \mathrm{~m} / \mathrm{s}$ & $6 \mathrm{~m} / \mathrm{s}$ \\
\hline Speciality & $\begin{array}{c}\text { Following } \\
\text { Waypoint } \\
\text { navigation } \\
\text { GIMBAL } \\
\text { payload }\end{array}$ & $\begin{array}{c}\text { Waypoint } \\
\text { navigation } \\
\text { Changeable } \\
\text { GIMBAL }\end{array}$ & $\begin{array}{c}\text { Differential } \\
\text { GPS } \\
\text { Waypoint } \\
\text { Navigation }\end{array}$ \\
\hline MC Price & $\$ 110,000$ & $\$ 100,000$ & $\$ 120,000$ \\
\hline
\end{tabular}

Like this, diversified miniature UAVs are developed at home and abroad and in this study, it is intended to be used for generation of 3D model and mesh image through image information acquisition by utilizing UAVs of commercial purpose.

\subsection{Set a target performance (criteria performance) of this research}

In order to select suitable model among models being surveyed in previous process, model sorting-out 
was started considering on-site condition. A model suitable for image information acquisition and data transmission was considered and it was decided to be applied to image processing technology for separating object information from 2D image information being collected by selected model.

First, through basic specification of disclosed equipments, 2 types of model were selected. Relevant model was divided into hobby purpose and industrial purpose and each one from relevant model was selected. Selected models were Phantom 2 Vision and DJI-S1000 and on-site test was performed based on relevant equipments. On-site test was mainly performed for equipment operation, image transmission environment, image quality, manipulation and the result of its performance is as follows.

*Experiment 1

Place: Pangyo KPM Head Office

Model: Phantom2 Vision

Max. speed: Over $50 \mathrm{~km} / \mathrm{h}$

Weight: $1,160 \mathrm{~g}$ performance

Performance test

- Operation(Flight) time: 30 minutes

- iPhone interfaced image transmission distance: App. $200 \mathrm{~m}$

- Payload: Camera 300g

- No sliding, trembling phenomenon at the time of turning

Problem: Occurrence of partial interruption phenomenon when transmitting WiFi. Flight instability in case of increase of separate payload in addition to camera

*Experiment 2

Place: Pangyo Hwarang Park

Model: DJI-S1000

Max. speed: Over $60 \mathrm{~km} / \mathrm{h}$

Performance Item:

-Auto-pilot test flight

-Performance item: Manual flight

Performance result:

- Auto-pilot: Automatic return after moving to a pre-set position

Position error between departure point and destination within 1m

- Manual flight: Flight without sliding, trembling even under wind speed of app. $5 \mathrm{~m} / \mathrm{s}$ at the time of test performance

Problem: Stable flight is enabled owing to drive of 8 propellers but a separate frame is required as propeller is exposed to outside.

\subsection{The selection and verification of optimal aerial movable image sensing platform}

Selected equipment through a test of on-site application being performed as above was DJI-S1000 and its detailed specification is as follows.

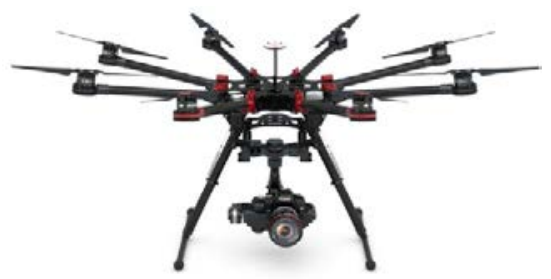

Figure 3 DJI-S1000

\begin{tabular}{|c|c|}
\hline size & $1100 \mathrm{~mm}$ \\
\hline weight & $4.2 \mathrm{~kg}$ \\
\hline material & carbon \\
\hline $\begin{array}{l}\text { control } \\
\text { range }\end{array}$ & $1 \mathrm{~km}$ or more \\
\hline $\begin{array}{l}\text { wind } \\
\text { resistance }\end{array}$ & $10 \mathrm{~m} / \mathrm{s}$ \\
\hline $\begin{array}{l}\text { maximum } \\
\text { altitude }\end{array}$ & $\begin{array}{c}\text { Camera, } \\
\text { Radiation Sensors }\end{array}$ \\
\hline flight time & $25 \mathrm{~min}$ \\
\hline payload & $5 \mathrm{~kg}$ \\
\hline features & $\begin{array}{c}\text { Vertical take-off and landing, } \\
\text { autopilot, } \\
\text { fixed position } \\
\text { Vertical and horizontal speed control }\end{array}$ \\
\hline
\end{tabular}

\section{Development of object extraction process}

\subsection{Obtaining information of on-site imagery and establishing the process of defining the surface mesh}

In order to actually use acquired information, on-site image and object information are collected by using image sensing platform. Image processing process of acquiring image information by using GCS system of movable sensing platform (UAV) and separating object information from 2D image information through this system is required.

Following is image information acquisition screen by using GCS system. 


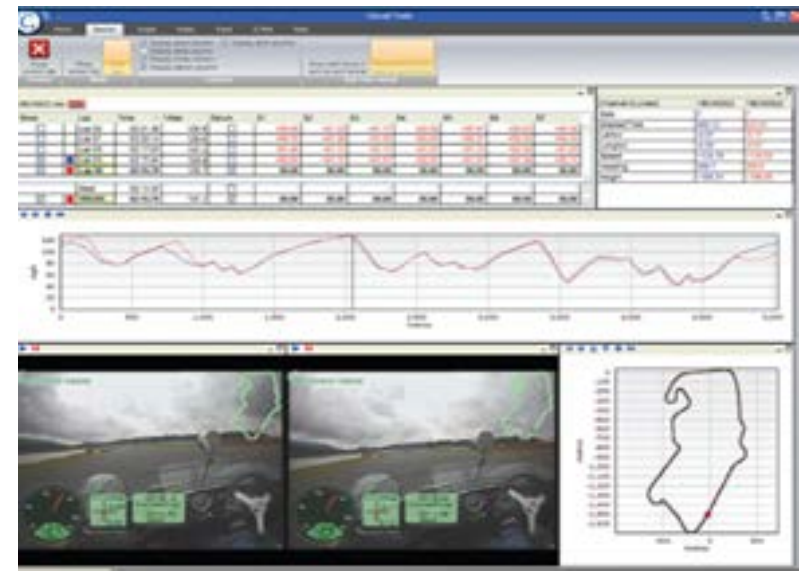

Figure 4 Image information acquisition screen by using GCS system

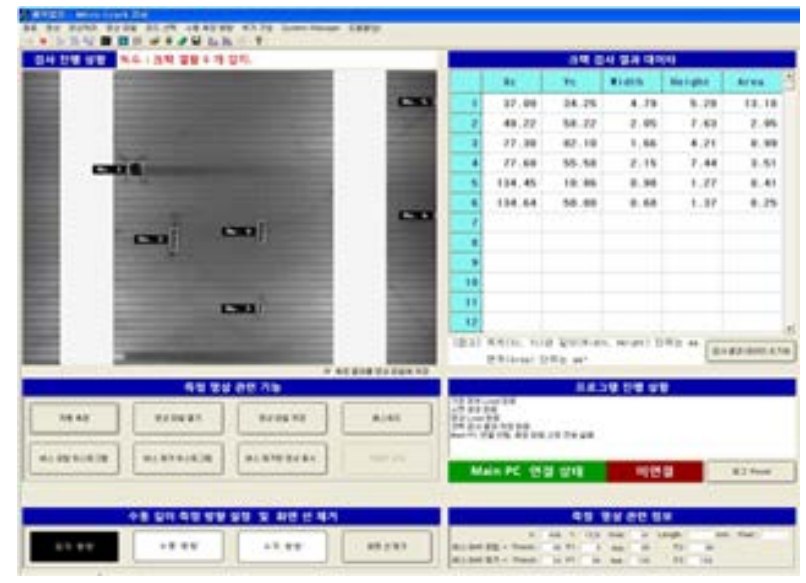

Figure 5 Analysis of image information

\subsection{Development of technology of collecting object information}

Acquired information is extracted as required object by using size, area and shape information. By using stereo vision, 3D information of object was extracted. Stereo vision is an equipment using a binary principle of human 2 eyes. 3D information of object is calculated from several images being photographed in mutually different place for the same object after watching object in different place and restoring distance by using its image difference.

In this study, 3D information extraction is enabled by finding out correct coordinates of 3D object based on stereo vision and this information will be used in the future.

Following photo shows object acquired from image in order to extract it.
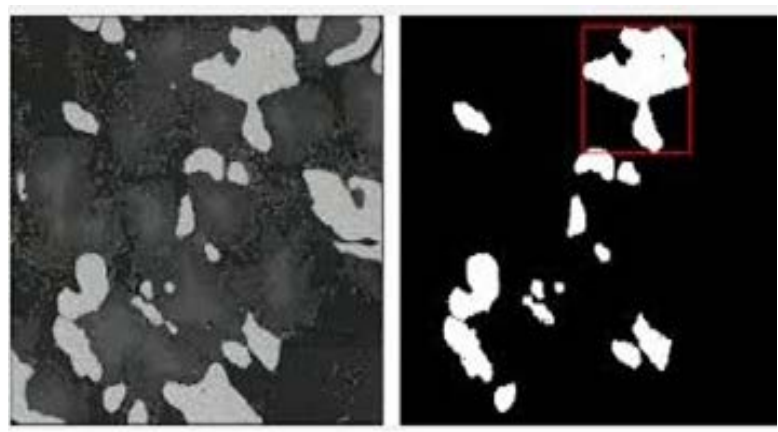

Figure 6 Object acquired from image in order to extract

Coordinates calculation formula and condition for utilizing stereo vision that is used in this study are as follows.

$$
\begin{gathered}
\mathrm{z}=\frac{(R h \times B 1)}{2 \times \tan (A v h) \times(P x 1-P x 2)} \\
x=\frac{B 1 \times(P x 1+P x 2-R h)}{2 \times(P x 1-P x 2)} \\
y=\frac{-B 1 \times(P y 1+P y 2-R v)}{2 \times(P x 1-P x 2)}
\end{gathered}
$$

Baseline: BI (Baseline) 2 sets of camera

Distance between centers. BI 3m at the time of test Camera viewing angle: Av (View Angle) $=2$ Avh.

At the time of test, Av is 70 “, Avh 35”

Horizontal resolution: Rh (Horizontal resolution)

At the time of test, Rh is 2592.

- Vertical resolution: Rv (Vertical resolution)

At the time of test, Rv is 1944.

\section{$5 \quad$ UAV acquisition image processing}

The acquired data is 2D image information. And 2D image information is converted to a $3 \mathrm{D}$ point cloud data. Since the cloud will merge the data. Taken place is Sungkyunkwan University area. Total aerial photography was carried out twice. Utilizing the DJI Vision App (iPhone Version) was camera controls. Obtain photos are a total of 60 chapters.

Conversion of the image was carried out through the following procedure.

- Feature Matching Using SIFT Algorithm through the two-dimensional image information obtained 
- Matching the data based on Sparse 3D data generation - camera location estimation and cloudgenerated data.

Dense 3D data generated using the CMVS / PMVS2 through -Sparse 3D data

- Create a 3D Point cloud data mesh screen work

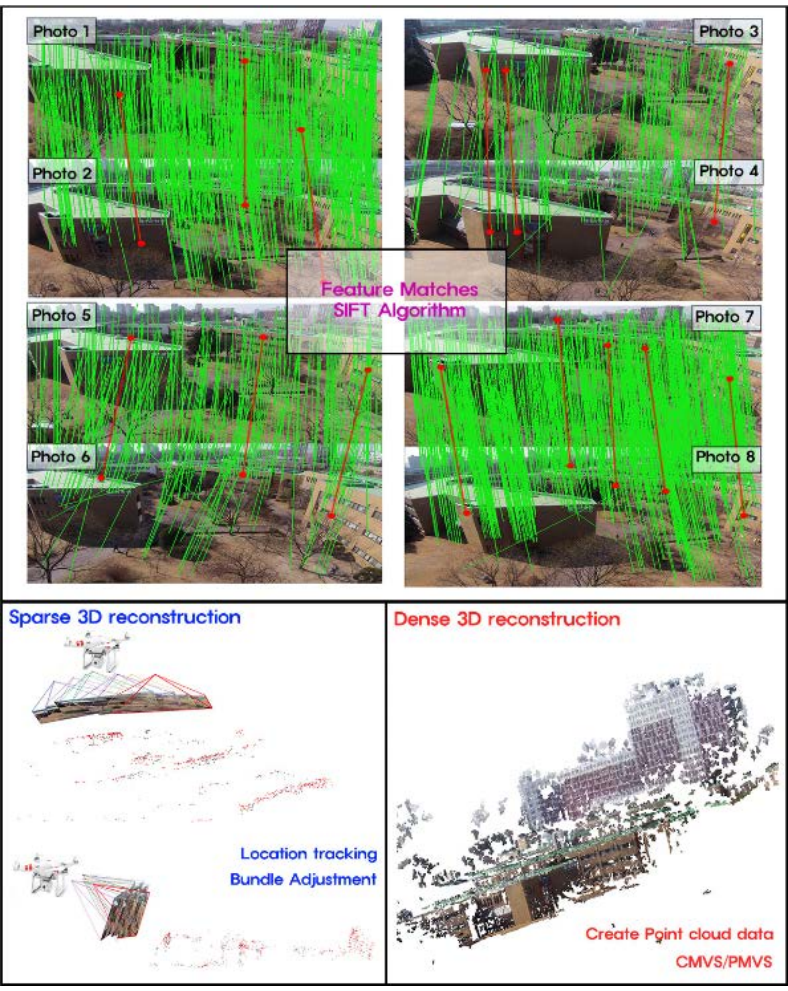

Figure 7 2D and 3D image matching

Algorithm extracted through the above procedure is as follows.

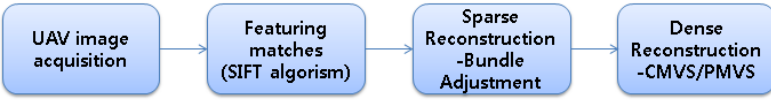

Figure 8 matching algorithm with UAV image

\section{Conclusion}

This study is regarding generation of civil 3D model and mesh image by using UAV as a part of technology that may improve construction quality, productivity and economic efficiency through informatization and efficient application of construction equipments in large-scaled earthwork project.

In order to acquire spatial information through UAV, UAVs of diversified types were surveyed and 2 types that are most suitable for current reality and on-site condition among those were sorted out. By using sorted 2 types of device, a test was progressed under similar on-site condition and one model among these was selected. Through relevant model, site photos and test data were acquired and 3D coordinates setting was made by using stereo vision and such data could be mapped out through 3D graphic process by which such coordinates could be confirmed visually.

It is considered that under the current construction site situation where dependability of construction machinery equipment is being increased day by day, this study would be helpful for solving the problem of decreased productivity and occurrence of various safety accidents due to lack of inter-equipment communication, provision of working information, construction error of unskilled workers and accumulated survey error.

\section{Acknowledgement}

This work is supported by Korea Minister of Ministry of Land, Infrastructure, Transport affairs as Convergence Engineering of Future City Master and Doctoral Grant Program

This research was supported by a grant(14SCIPB079344-01) from Smart Civil Infrastructure Research Program funded by Ministry of Land, Infrastructure and Transport(MOLIT) of Korea government and Korea Agency for Infrastructure Technology Advancement (KAIA).

\section{References}

[1] P. Doherty, P. Haslum, F. Heintz, T. Merz, P. Nyblom, T. Persson, B. Wingman “A Distributed Architecture for Autonomous Unmanned Aerial Vehicle Experimentation " . Distributed Autonomous Robotic Systems 6, 2007, pp 233-242

[2] Stephen R. Dixon, Christopher D. Wickens “ Automation Reliability in Unmanned Aerial Vehicle Control: A Reliance-Compliance Model of Automation Dependence in High Workload" , Human Factors: The Journal of the Human Factors and Ergonomics Society Fall 2006 vol. 48 no. 3 474-486

[3] Barazzetti, L.; Remondino, F.; Scaioni, M. Automation in 3D reconstruction: Results on different kinds of close-range blocks. Int. Arch. Photogramm. Remote Sens. Spatial Inf. Sci 2010, 38, Part 5. 55-61

[4] Barazzetti, L.; Remondino, F.; Scaioni, M.; Brumana, R. Fully automatic UAV image-based sensor orientation. Int. Arch. Photogramm. Remote Sens. Spatial Inf. Sci 2010, 38, Part 5. 6.

[5] Scaioni, M.; Barazzetti, L.; Brumana, R.; Cuca, B.; Fassi, F.; Prandi, F. Rc-Heli and Structure \& 
Motion Techniques for the 3-D Reconstruction of a Milan Dome Spire. Proceedings of the 3rd ISPRS International Workshop 3D-ARCH 2009:

“3D Virtual Reconstruction and Visualization of Complex Architectures” , Trento, Italy, 25-28, February 2009; p. 8.

[6] Nebiker, S.; Annena, A.; Scherrerb, M.; Oeschc, D. A light-weight multispectral sensor for micro UAV-Opportunities for very high resolution airborne remote sensing. Int. Arch. Photogramm. Remote Sens. Spatial Inform. Sci 2008, 37, Part 1. 1193-1198. 